\title{
PERFILES CONSTITUCIONALES DE LA CARTA ENCÍCLICA "LAUDATO SI": UN ANÁLISIS DESDE LA ANTROPOLOGÍA ECONÓMICA
}

\author{
CARTA ENCÍCLICA “LAUDATO SI"FROM A CONSTITUTIONAL PERSPECTIVE: \\ ECONOMIC ANTHROPOLOGY ANALYSIS
}

\author{
Víctor Meseguer Sánchez \\ Dr. en Derecho. Licenciado en Derecho \\ Director Cátedra Internacional de RSC Universidad Católica de San Antonio de Murcia \\ E-mail:jvmeseguer@ucam.edu
}

Gabriel López Martínez

Dr. Europeo en Filosofía. Licenciado en Antropología Social y Cultural Investigador de la Cátedra Internacional de RSC Universidad Católica de San Antonio de Murcia

E-mail:lpzspk@gmail.com

Convidados

RESUMEN: Este artículo se ocupa de analizar la carta encíclica de Francisco I "Laudato sí", entendida como la "cara medioambiental de los derechos humanos", con la intención de poner en relación las propuestas del Papa con teorías sociales, culturales y filosóficas contemporáneas en consonancia con esta reflexión. En concreto, este trabajo se ocupa de revisar los capítulos 3 y 4 del texto del Papa Francisco desde la perspectiva de la Antropología Económica, una disciplina que entendemos que permite una aproximación integral a esta aproximación. En este sentido, se ofrece una breve revisión de la literatura más relevante en esta materia, de manera que sirva para introducir y contextualizar nuestro análisis.

Palabras clave: Derecho ambiental constitucional. Laudato si; Antropología Económica; Derechos Ecológicos.

\begin{abstract}
This article aims to analyze Francisco I Circular 'Laudato si', as it may be undestood as the 'environmental side of Human Rights', in order to relate its proposals to other contemporary social, cultural and philosophical theories. In particular, we focus on Chapters 3 and 4, and we approach to this text from the perspective of Economic Anthropology since it allows an integral and complete interpretation. In this sense, we offer a brief review of the most relevant literature concerning this matter, in order to introduce and contextualize our analysis.

Keywords: Enviromental constitutional Laudato si; Economic Anthropology; Ecological Rights.

CONTENIDO: Prenotandos Constitucionales. 1. Antropología económica: Una aproximación a su objeto de estudio. 2. Ser humano y naturaleza: Consideraciones en torno a un paradigma dominante. 3. Análisis de la carta encíclica "laudato si": Capítulos tercero y cuarto capítulo 3.1 Capítulo 3. Raíces humanas de la crisis ecológica. 3.2 capítulo 4 hacia una "ecología integral”. Conclusiones.
\end{abstract}




\section{PRENOTANDOS CONSTITUCIONALES}

"El ser humano no es plenamente autónomo. Su libertad se enferma cuando se entrega a las fuerzas ciegas del inconsciente, de las necesidades inmediatas [...] está desnudo y expuesto frente a su propio poder, que sigue creciendo, sin tener los elementos para controlarlo" (Laudato si, Capítulo 3, página 3).

El Derecho Constitucional posee una visión multidisciplinar que comparte contenidos con las preocupaciones del derecho administrativo, el civil, incluso el mercantil y las necesidades de carácter económico de la sociedad y sus agentes, que en la actualidad se nutren de los presupuestos democráticamente aceptados por la mayoría en cumplimiento de los parámetros de la Democracia y el Estado de Derecho. Recoge además de las concretas referencias normativas que determinan la convivencia pacífica en sociedad, los principios que orientan la actividad de las instituciones y de los ciudadanos. Por ello surge dentro del marco constitucional la dimensión axiológica más concreta de los ordenamientos jurídicos y especialmente en cuanto a la ecología la protección y defensa de los recursos naturales y el necesario equilibrio con el crecimiento económico para fijar un desarrollo sostenible que garantice las necesidades de la humanidad presente y futura1. Los enunciados de la Constitución ponen de manifiesto con carácter general su condición instrumental al servicio de los poderes públicos, para el desarrollo de los compromisos políticamente adquiridos por los poderes del Estado. En este sentido, las constituciones de la modernidad formulan consideraciones impositivas sobre los poderes públicos que deben garantizar las promesas y compromisos electorales, las necesidades sociales a través de la dotación de medios para su consecución y dentro de ellas es urgente poner de manifiesto la supervivencia de la especie que lleva aparejada la protección de la Naturaleza. Las consideraciones que se abordan a continuación ponen de manifiesto alternativas posibles para cumplir con las exigencias de desarrollo y compromiso con los derechos humanos, la dignidad de la persona y la ecología desde la encíclica Laudato si que tiene en común con las normas políticas que las constituciones representan el que cumplen con las exigencias de función social al servicio del bien común y a la garantía del interés general.

Ciertamente en los últimos tiempos en su primera encíclica, Francisco I llama la atención sobre la necesidad de cambiar un estilo de vida que avanzaría hacia una destrucción ambiental y humana. Así, el texto "Laudato si"”, que hace referencia al cántico a las criaturas de San Francisco de Asís, expresa en términos generales que la naturaleza no puede entenderse como objeto o posesión humana, sino como hermana o madre. En este sentido, cuando hablamos de "medio ambiente" deberíamos atender a la relación existente entre el ser humano y la naturaleza, y en concreto al vínculo que cada sociedad, en cuanto ecosistema, establece con su entorno más próximo.

El texto advierte de la necesidad de adoptar una visión global que entienda la interdependencia de las distintas instituciones que conforman una sociedad determinada. Se propone, además, el cuestionamiento del "paradigma dominante"2 y homogeneizador que vincularía progreso tecnológico con bienestar y mejora de las condiciones de vida. A partir de ahí, propone una necesaria "revolución cultural" que, entre sus diferentes retos, destaque la

\footnotetext{
${ }^{1}$ En este sentido destacan las aportaciones que desde el campo constitucional realiza la profesora MÉNDEZ ROCASOLANO ,enEl Derecho, el hombre y la Tierra. Fundamentos y defensa jurídica del Derecho al medio ambiente, Dykinson 2017, en la que conecta directamente los valores superiores del ordenamiento jurídico con el derecho al medio ambiente adecuado para el desarrollo de la persona del artículo 45. Interesa destacar especialmente la aportación que realiza mediante la "dinamogénesis de los derechos" en la que configura el contenido esencial del derecho público subjetivo al "entorno Vital".

${ }^{2}$ "Se vuelve indispensable crear un sistema normativo que incluya límites infranqueables y asegure la protección de los ecosistemas, antes que las nuevas formas de poder derivadas del paradigma tecnoeconómico terminen arrasando no sólo con la política sino también con la libertad y la justicia" (Cap. 3, p. 43, 53).
}

Revista de Direito Brasileira | São Paulo, SP | v. 20 | n. 8 | p. 364-377 |Mai./Ago. 2018 
urgencia de aminorar el ritmo de crecimiento. ${ }^{3}$ Se trataría de una revolución que debe comenzar por un cuestionamiento antropológico, esto es, una reconsideración del papel del ser humano como "generador" de instituciones culturales (Economía, Ecología, entre otras) que se presentan como esferas aisladas, con sus propias lógicas y precintadas por dogmas reduccionistas ${ }^{4}$. En el cuestionamiento de la mirada unidimensional cabe adelantar los trabajos de Karl Polanyi (1989) como representante de la corriente llamada sustantivista ${ }^{5}$, sobre la que se avanzará en su desarrollo en apartados posteriores.

Este trabajo se ocupa de revisar las propuestas de la encíclica "Laudato si", con la intención de establecer paralelismos entre las reflexiones del texto de Francisco I y diferentes corrientes de pensamiento y teorías que apuntan hacia esta línea de debate, y que estarían vinculadas al ámbito de estudio de la Antropología Económica. Con este propósito, en primer lugar, se ofrece una breve descripción de la evolución de esta disciplina académica, para así situar sus posibilidades de aplicación. En segundo lugar, se propone una revisión del cambio de interpretación que ha sufrido el concepto de "naturaleza" a lo largo de la historia, ya que la encíclica se ocupa en gran medida de analizar la relación entre hombre y naturaleza, y a partir de ahí sobre las implicaciones sociales y culturales. En último lugar, se analizan los capítulos 3 y 4 de la encíclica del Papa Francisco donde se ocupa de las "causas y raíces humanas de la crisis ecológica" y de la concepción de "una ecología integral", respectivamente, poniéndose en el contexto de diferentes teorías de lo social, y en este ámbito concreto antropológico referido.

\section{ANTROPOLOGÍA ECONÓMICA: UNA APROXIMACIÓN A SU OBJETO DE ESTUDIO}

"La Antropología económica no se ha limitado a replicar las actividades que los conomistas hacen en nuestra sociedad, sino que se ha ocupado de recoger y sistematizar información etnográfica sobre el conjunto de instituciones que han permitido a un amplio rango de sociedades obtener sus medios de vida" (Molina y Valenzuela, 2007: 53).

La literatura referida a la disciplina de la Antropología Económica suele situarla en tres ámbitos de actuación: a) el debate en relación a la economía neoclásica, b) su relación con la ecología y c) el concepto de distribución de los mercados. Podríamos también referirnos a un cuarto campo: aquel que distingue entre "economía política" y "ecología política" como dos ámbitos de actuación diferentes y propios de la Antropología Económica (Comas D’Argemir, 1998).

En primer lugar, sería necesario situar el origen de los preceptos defendidos por los denominados "economistas neoclásicos", para así avanzar en el proceso de constitución de la economía como esfera autónoma del resto de instituciones sociales y, en consecuencia, un paradigma que maneja sus leyes propias en virtud de lógicas que a menudo parecen incuestionables. De manera breve, sin detenernos en una revisión de historia económica abultada,

\footnotetext{
${ }^{3}$ Son muchas las voces que desde el mundo académico cuestionan la vinculación de crecimiento económico con bienestar social, y que proponen la necesidad de un cambio en las relaciones que se establecen entre los individuos y de éstos con respecto a la naturaleza. Desde esta perspectiva surge el concepto de "decrecimiento", que vendría a reconsiderar el alcance del término "desarrollo sostenible", y que se presenta como un nuevo paradigma ecologista. Para avanzar en esta idea, véanse los trabajos de TAIBO, Carlos (2011). y NAREDO, José Manuel (2010).

4، $\mathrm{Si}$ el ser humano se declara autónomo de la realidad y se constituye en dominador absoluto, la misma base de su existencia se desmorona [...] No habrá una nueva relación con la naturaleza sin un nuevo ser humano. No hay ecología sin una adecuada antropología" (Cap. 3, p. 9).

${ }^{5}$ En contraposición a la llamada corrienteformalista, desde la perspectiva sustantivista se cuestiona que la acción económica se desarrolle separada de los marcos históricos, culturales e institucionales. Afirman desde esta perspectiva que "los orígenes étnicos, las estructuras de parentesco, los valores culturales y las relaciones sociales son importantes para explicar los fenómenos económicos" (MOLINA y VALENZUELA, 2007:16).
}

Revista de Direito Brasileira | São Paulo, SP | v. 20 | n. 8 | p. 364-377 |Mai./Ago. 2018 
podemos situar el inicio de esta lógica concreta en las consecuencias derivadas de la Revolución Industrial.

\begin{abstract}
“¿Qué significa la frase 'estalló la Revolución Industrial'? Significa que un día entre 1780 y 1790 , y por primera vez en la historia humana, se liberó de sus cadenas al poder productivo de las sociedades humanas, que desde entonces se hicieron capaces de una constante, rápida y hasta el presente ilimitada multiplicación de hombres, bienes y servicios [...] Sus más graves consecuencias fueron sociales: la transición a la nueva economía creó miseria y descontento, materiales primordiales de la revolución social " [...] Sin embargo, desde el punto de vista de los capitalistas, esos problemas sociales solo afectaban al progreso de la economía si, por algún horrible accidente, derrocaran el orden social establecido" (Hobsbawm, 2009: 35, 46).
\end{abstract}

Esta "liberación de las cadenas" del poder productivo significaría la conversión que experimentó "lo económico/productivo" para convertirse en una esfera independiente, con sus propias lógicas y reglas de funcionamiento, desvinculada del resto de instituciones sociales y culturales. Es en este aspecto donde encontramos lo que podríamos denominar un giro económico-céntrico, si se permite esta expresión, entendido como cambio de paradigma: nuevas relaciones laborales, nueva relación hombre-naturaleza, nueva relación (económica) entre los sujetos, y de éstos con respecto al Estado.

Con el interés de contextualizar, avanzaremos hasta situarnos en un momento contemporáneo y así exponer que estos principios neoliberales son retomados a partir de los años 60 del siglo pasado por los llamados teóricos formalistas. Desde esta perspectiva se defiende aquella idea que entiende la economía como la ciencia de la escasez, de manera que el individuo actuará racionalmente para satisfacer sus necesidades. Además, se entiende que esta pauta de comportamiento, esto es, la decisión racional maximizadora, será la misma en todas partes -una lógica que avanza hacia la configuración de un paradigma homogéneo que estandariza el comportamiento económico-. Podemos referirnos a Herskovits (1952) como uno de los principales representantes de esta perspectiva, defendiendo esta conducta racional individual como algo ya existente, con las mismas características, en las "sociedades primitivas".

En contra de estos preceptos, encontramos los argumentos defendidos por quiénes han venido a llamarse sustantivistas. Al contrario que aquellos formalistas, el sustantivismo niega que la acción económica se desarrolle separada de los marcos históricos, culturales e institucionales. Afirman desde su interpretación de la realidad que "los orígenes étnicos, las estructuras de parentesco, los valores culturales y las relaciones sociales son importantes para explicar los fenómenos económicos" (Molina y Valenzuela, 2007:16). De estos autores sustantivistas, nos parece que Karl Polanyi sería el representante más significativo, ocupado por entender los sistemas económicos a lo largo de diferentes periodos históricos. Su trabajo explica cómo la economía se ha separado del resto de instituciones sociales en un momento concreto, separación que, por lo demás, no debería ser considerada como una característica inherente al fenómeno de lo económico.

"Por económico solemos entender al menos dos cosas diferentes. Por una parte las actividades, indicadores o procesos que tienen que ver con la creación, distribución o consumo de bienes y servicios, es decir, un sector de la cultura; por otra, las acciones motivadas por el cálculo racional que buscan maximizar el beneficio u optimizar los medios en relación a los fines, esto es, una modalidad de conducta. Estas dos acepciones de la palabra "economía", pueden denominarse "substantiva" y "formal" respectivamente" (Polanyi, 1989: 215).

Por tanto, la teoría sustantivista niega la existencia de aquel concepto de escasez defendido por aquellos formalistas y que ocupa el argumento neoliberal contemporáneo. Explica

Revista de Direito Brasileira | São Paulo, SP | v. 20 | n. 8 | p. 364-377 |Mai./Ago. 2018 
así que esta pretendida escasez será una condición ideológica derivada de la economía capitalista de mercado, y no una condición existencial del hombre. De este modo, Polanyi critica la lógica del denominado homo oeconomicus: un producto del capitalismo moderno, nacido en un contexto en el que domina la lógica de mercado que "subordina lo social, destruye las comunidades indígenas y las formas de vivir comunitarias, e impone la pobreza y el desarraigo en aras de la obtención del máximo beneficio" (Comas d'Argemir, 1998: 141).

"A diferencia del pensamiento marxista, según el cual el nacimiento del capitalismo industrial causa considerables perjuicios económicos a la mano de obra, Polanyi quiere demostrar que la emergencia de la economía de mercado es, ante todo, un cataclismo cultural" (Mancourt, 2006: 93).

En último lugar, y dada la vinculación con respecto al texto de Francisco I, nos parece relevante referirnos a la distinción que proponemos entre "economía política" y "ecología política". Desde la primera óptica, el interés de análisis se centra en las formas de acceso a la riqueza y al poder, "tal y como se concreta en los procesos de trabajo y con sus implicaciones en la conformación de jerarquías sociales" (Comas d'Argemir, 1998: 12). Principalmente, se ocuparía de dos aspectos: los procesos de producción y de distribución, y a partir de aquí se interesa por las dimensiones sociales, políticas y culturales con respecto a estos procesos económicos. Por lo tanto, la "economía política" maneja un concepto de cultura que pone en relación estos procesos económicos con aspectos sociales, políticos y culturales de manera amplia. En este sentido, lo relevante al acercarnos al estudio de una cultura, será atender a la relación o articulación que se da entre los procesos históricos y sociales globales y de larga duración. La cultura no puede existir al margen de estos procesos, y "se entiende que los símbolos y significados son indisociables, a su vez, de los componentes materiales y de las relaciones sociales" (Comas d'Argemir, 1998: 16). Esto se traduce en la necesaria existencia de una heterogeneidad cultural que, en lo económico, se opone a la homogeneización que el propio Francisco I critica en su Carta Encíclica, y que parece extenderse desde los preceptos de un nuevo paradigma que interviene también en la naturaleza.

Por su parte, la llamada "ecología política", surgida en los años 80 del siglo pasado, amplía la perspectiva de la economía política hacia enfoques que tienen en cuenta la interacción de la actividad humana con el medio ambiente. Se propone así modificar o completar los planteamientos existentes desde la llamada "ecología cultural"6, introduciendo una dimensión política en su análisis. Desde esta perspectiva interesa analizar principalmente las diferencias sociales en el acceso a los recursos, estudiando en este punto los efectos sobre el medioambiente, así como la articulación entre los contextos locales y la globalidad. Podemos observar que esta "ecología política" está muy en consonancia con las propuestas de Francisco I, en concreto con aquella necesaria "revolución cultural" que pasa por un cambio de interpretación y de "uso" de lo material que, en su última etapa o al mismo tiempo, afecta a las relaciones entre humanos y de éstos con respecto a la naturaleza.

"Hoy se puede hablar de la ecología política como un campo específico de interés y de investigación, pero se trata de algo muy reciente, puesto que el volumen de trabajos significativos se ha producido en los últimos quince años. [...] En todo caso, tres autores aparecen como los más citados: Eric Wolf, Karl Polanyi y Clifford Geertz: Wolf por ser quién por primera vez utiliza el término

\footnotetext{
${ }^{6}$ La Ecología Cultural se ocupa de "buscar" y analizar los rasgos culturales particulares propios de un "área cultural" concreta. En términos muy generales, podemos decir que esta perspectiva se diferencia de los ecólogos humanos que se ocuparían de buscar principios ecológicos universales; mientras que la ecología cultural atiende a estas diferencias propias de un territorio concreto, en virtud de sus instituciones propias que la diferencias de otras "áreas". Para abundar en esta disciplina, véase WHITE (1949) y STEWARD (1955).
} 
y los otros dos porque aplican en la práctica este tipo de enfoque en sus trabajos" (Comas d'Argemir, 1998: 139).

No nos extenderemos en esta delimitación del campo de actuación de la disciplina de la Antropología Económica. El interés está en plantear este campo como un marco teórico a partir del cual debatir los planteamientos que se exponen en el texto del Papa Francisco I. En los apartados en los que se analizan los capítulos del texto del Sumo Pontífice referidos a la "crisis ecológica", se vinculará su propuesta con los presupuestos de esta disciplina. A continuación, se repasa la relación hombre-naturaleza y sus diferentes interpretaciones y perspectivas hasta llegar al paradigma que parece dominar en la actualidad.

\section{SER HUMANO Y NATURALEZA: CONSIDERACIONES EN TORNO A UN PARADIGMA DOMINANTE}

"La intervención humana en la naturaleza siempre ha acontecido [...] Se trataba de recibir [...] En cambio ahora lo que interesa es extraer todo lo posible de las cosas por la imposición de la mano humana" (Laudato si, Capítulo 3, pág. 3).

A lo largo de la Historia, hemos ido construyendo diferentes ideas acerca de lo que es naturaleza. En un primer acercamiento, siguiendo a Gudynas ${ }^{7}$ podemos decir que esas concepciones han evolucionado desde la noción de naturaleza como algo salvaje e incontrolable, que generaría incluso terror, pasando por la naturaleza entendida como "canasta de recursos", es decir, la idea de que la manipulación, dominación y control de la naturaleza nos permite la subsistencia. En ambos casos, estamos ante lógicas hegemónicas que persisten en cada momento histórico, de modo que en la actualidad la naturaleza parece absorbida por la ideología neoliberal que la entiende como "capital ambiental". Se trata, como ya hemos avanzado, del dominio técnico sobre la naturaleza que se hace cada vez más evidente a medida que avanza el proceso de industrialización.

"El siglo XIX es el siglo de los ingenieros. Encauzan ríos permanentemente, construyen presas, secan zonas pantanosas, paran dunas móviles y hacen de la selva un dominio forestal. Si hasta ese momento el hombre se sentía presa de los caprichos de la naturaleza, a partir de ahora crece la conciencia de, si no dominar su fuerza, por lo menos poder dirigirla" (Schriewer, 2012: 14-15).

Con estos nuevos ropajes, la consecuencia lógica es que sólo se invertirá, se prestará atención, en aquello que es rentable, lo que da lugar a una fragmentación de la idea de naturaleza en diferentes elementos de los que entresacamos solamente aquellos que económicamente consideramos aceptables. De esta forma, nos encontramos, por ejemplo, con grandes corporaciones que luchan por poseer patentes y otros derechos de propiedad ${ }^{8}$ sobre esta "naturaleza fragmentada". Esta idea de "naturaleza fragmentada" será el reflejo de la segmentación de la humanidad, principalmente entre aquellos que son productivos y rentables económicamente y los que no lo son y, por tanto, sufren las consecuencias de lo que se ha dado en llamar "crisis de civilización", por lo multidimensional de los elementos que la conforman.

\footnotetext{
${ }^{7}$ GUDYNAS (2004: 10).

${ }^{8}$ Para el análisis de un caso de estudio amplio de la actuación durante décadas de una empresa transnacional sobre un territorio, véase el trabajo de investigación de MESEGUER SÁNCHEZ, V. (2016).

"'Como ejemplos de crisis de civilización en el pasado podemos citar los casos de la caída del Imperio Romano, las Guerras de Religión que asolaron Europa en los siglos XVI y XVII, y la Segunda Guerra Mundial. En los tres casos, a mi modo de ver, se observa que el sistema institucional que estaba vigente en cada uno de ellos estuvo al borde del precipicio" (MARTÍNEZ NAVARRO, E., 2007: 3-4).
} 
El Papa Francisco I señala en su texto que la raíz de los conflictos identificados estaría en un estilo de vida concreto que viene determinado por el "paradigma tecnocrático". Según esta propuesta, el desarrollo de la técnica se vincula al aumento del bienestar, y trae consigo conceptos como el de crecimiento infinito o el de equilibrio de mercado. Se trata pues de un paradigma instrumental, que domina la economía y la política ${ }^{10}$, y que está circunscrito a la especialización como forma de compartimentar, extraer y obtener rédito de los "objetos" a disposición del hombre. Además, estamos ante una lógica de acción homogeneizadora que trasciende las fronteras y que, en palabras de Bauman, daría lugar a un divorcio entre poder y política: "Hoy tenemos un poder que se ha quitado de encima a la política y una política despojada de poder. El poder [financiero, instrumental, depredador] es ya global; la política sigue siendo lastimosamente local" $" 11$.

En este paradigma, donde las voces críticas a menudo suenan marginales, se conforma un determinado tipo de sujeto: "un concepto del sujeto que progresivamente, en el proceso lógico-racional, abarca y así posee el objeto que se halla afuera". Se trataría de un individuo que adolece de un antropocentrismo desmesurado, con una forma concreta - distorsionada- de percibir su entorno más próximo. Y es aquí donde se urge a un "replanteamiento antropológico" que invita a repensar las relaciones que se establecen entre individuos y comunidades, y a "graduar" la mirada unidireccional instalada en los individuos.

\begin{abstract}
"Vivimos y morimos racional y productivamente. Sabemos que la destrucción es el precio del progreso [...] que los negocios deben ir adelante y que las alternativas son utópicas. Esta ideología pertenece al aparato social establecido; es un requisito para su continuo funcionamiento y es parte de su racionalidad" (Marcuse, H., 1968: 171).
\end{abstract}

Esta racionalidad a la que se refiere Marcuse debería ser cuestionada, y plantear alternativas a este modelo capitalista que proyecta lógicas que desvirtúan las relaciones humanas. En este sentido, nos interesa detenernos en las características de lo que se ha venido a llamar Producción Mercantil Simple (PMS), entendido como aquel modo de producción que tradicionalmente ha sido estudiado en comunidades de pequeños campesinos y artesanos. Se refiere a aquellos que no explotan el trabajo ajeno, sino que son al mismo tiempo propietarios de los medios de producción y mano de obra productora: poseen las fuerzas productivas y organizan las relaciones de producción ${ }^{12}$. No se trata de sociedades prístinas idealizadas, sino que encontramos numerosos ejemplos contemporáneos en asociaciones de pescadores, campesinos autónomos y otros profesionales que optan por esta cultura productiva. Sería interesante profundizar en algunos trabajos que en los últimos años se han venido publicando, y que desde una metodología de análisis cualitativo despliegan etnografías que permiten conocer las formas de vida de algunas comunidades que se relacionan de esta manera con su actividad profesional y con su entorno 13 .

Por tanto, se puede afirmar que existen alternativas, ejemplos prácticos y actuales que demuestran otros modos de relación hombre-naturaleza. No nos referimos a episodios esporádicos ni vinculados a una relación de ocio con la naturaleza, sino a relaciones de trabajo y

\footnotetext{
${ }^{10} \mathrm{La}$ encíclica se refiere al problema del inmediatismo político, ocupado en el crecimiento a corto plazo, olvidándose de marcar objetivos a largo plazo que tengan en cuenta el bien común.

${ }^{11}$ BAUMAN, Z. (2011). Daños colaterales. Desigualdades sociales en la era global, Madrid, Siglo XXI.

${ }^{12}$ Recordemos que las fuerzas productivas se refieren a la parte material, al conjunto de los medios de producción y también a los recursos humanos empleados en la producción de bienes -herramientas, aperos, conocimientos técnicos, recursos naturales-. Por su parte, las relaciones de producción están compuestas por el conjunto de relaciones económicas que se establecen entre las personas.

${ }^{13}$ Para profundizar en la teoría de este modo de producción y analizar ejemplos prácticos, véanse los trabajos de HØJRUP (2003), CAYUELA SÁNCHEZ (2014), LÓPEZ MARTÍNEZ (2016), SCHRIEWER (2012), entre otros.
}

Revista de Direito Brasileira | São Paulo, SP | v. 20 | n. 8 | p. 364-377 |Mai./Ago. 2018 
naturaleza. En este punto, debemos detenernos en lo que se denomina el Conocimiento Ecológico Tradicional, que encuentra sus fundamentos en el llamado Conocimiento Indígena al que hace referencia Roy Ellen (1998).

"Por conocimiento ecológico tradicional se entiende la suma de datos, información e ideas adquiridas por un grupo humano, sobre su medioambiente, como resultado del uso y ocupación de un territorio durante muchas generaciones. (...) El conocimiento ecológico de los pescadores es una especialización del conocimiento ecológicotradicional. (...) El conocimiento ecológico de los pescadores, al carecer de reconocimiento social e institucional, como un tipo de saber válido, adolece también del apoyo socio-político y económico necesario para generar más y mejor conocimiento" (García-Allut, 2004: 35).

Como caso concreto de aplicación de estos preceptos, podemos detenernos en el sector pesquero, y en concreto en las propuestas del antropólogo Antonio García-Allut. Sus trabajos más recientes están vinculados a su propia experiencia profesional como emprendedor social a través de la implementación de distintos proyectos que pretenden crear un modelo integral y sistémico para hacer viable económica y socialmente la pesca artesanal ${ }^{14}$. Este antropólogo entiende que la pesca a pequeña escala, al carecer de representatividad efectiva en los órganos de decisión política, quedará a merced del poder de los intereses económicos de las grandes empresas pesqueras. Partiendo de esta premisa, propone que el tipo de pesca denominada como artesanal, al posibilitar una explotación más racional y equitativa de los recursos pesqueros, contribuye al mantenimiento de la biodiversidad de los ecosistemas marinos, y especialmente favorece la reproducción social de aquellos grupos humanos que dependen de esta actividad.

El Conocimiento Ecológico Tradicional no debe entenderse por tanto como un vestigio romántico, vinculado a sociedades prístinas. Al contrario, se trata de una visión vinculada al proceso económico, y que puede relacionarse con este modo de Producción Mercantil Simple:

"El sistema de producción mercantil simple es aquel que tradicionalmente ha sido estudiado en comunidades de pequeños campesinos y artesanos. Esta clasificación se refiere a aquellos que no explotan el trabajo ajeno, sino que son al mismo tiempo propietarios de los medios de producción y mano de obra productora. Siguiendo el esquema que propusimos anteriormente, se trata de aquellos individuos que poseen las fuerzas productivas y al tiempo organizan las relaciones de producción” (López Martínez, 2016: 42).

Entendemos la co-existencia de este sistema productivo con el sistema capitalista hegemónico, de manera que se presenta como una alternativa que implica un cambio de paradigma cultural: plantea otra forma de relación hombre-trabajo, y de éste con respecto a la naturaleza. Además, la PMS vincula aspectos como el parentesco en el sistema productivo: “(...) la propiedad de la empresa y el aprovisionamiento de mano de obra se combinan en el hogar. Como resultado de ello hay solo una clase directamente implicada en la producción y distribución del producto" (Friedmann, 1980: 172). Son varios los trabajos que han ido apareciendo, investigaciones que, en los sectores de la agricultura y la pesca ${ }^{15}$, se interesan por las posibilidades de la PMS como forma de entender el desempeño de una profesión atendiendo a lo local, y con una mirada inclusiva con respecto a la naturaleza.

\footnotetext{
${ }^{14}$ Para profundizar en su propuesta, véase www.fundacionlonxanet.org Página web consultada el 25 de noviembre de 2017.

${ }^{15}$ Véase LÓPEZ MARTÍNEZ (2016). En el caso de la agricultura, véase CAYUELA SÁNCHEZ (2014).
}

Revista de Direito Brasileira | São Paulo, SP | v. 20 | n. 8 | p. 364-377 |Mai./Ago. 2018 
En último lugar, en relación a este vínculo hombre-naturaleza, nos interesa indicar la necesidad de una "pedagogía integral" que conciencie y rescate aquella concepción de una naturaleza que trasciende su condición contemporánea de objeto. Este tipo de pedagogía -que en esencia podría llamarse revolucionaria al intentar frenar la lógica que entiende la naturaleza al servicio del hombre- no deberá interpretarse como casos aislados ni espontáneos, sino como un medio propuesto desde lo político, a través de una planificación en el ámbito educativo. Es desde esta concienciación temprana donde cabrá una relación persona-naturaleza integral e interiorizada, que propicie una construcción social "renovada" que cuestiona, además, la inercia de lo hegemónico. Refiriéndose a la ecología política se ha manifestado Mendez Rocasolano cuando habla de la ampliación de derechos en los que debería figurar el derecho al ambiente y al desarrollo sostenible ${ }^{16}$.

\section{ANÁLISIS DE LA CARTA ENCÍCLICA “LAUDATO SI": CAPÍTULOS TERCERO Y CUARTO}

En este apartado nos ocupamos del análisis de los capítulos 3 y 4 de la Carta Encíclica de Francisco I. Se trata de una revisión que vincula la propuesta del Sumo Pontífice con diferentes teorías y preceptos sociológicos y antropológicos contemporáneos, de modo que permita abrir una línea de debate que reconozca la posibilidad de visibilizar estas propuestas, otorgándole la importancia que desprende, y en este sentido, dejando patente que se trata de voces que también se dibujan desde el ámbito académico.

\subsection{Capítulo 3. Raíces humanas de la crisis ecológica}

Este Capítulo Tercero comienza cuestionando la relación que el hombre establece con la tecnología. Se entiende que ésta debería ser un medio que sirva para la consecución de objetivos concretos, haciendo más cómoda la vida de las personas. Sin embargo, se argumenta que la tecnología, vinculada al paradigma homogéneo y unidimensional ${ }^{17}$, se posiciona como instrumento de poder y dominación, permitiendo que el "sujeto" abarque y posea el "objeto" que se encuentra fuera de él. En este sentido, por objeto se entiende a la propia naturaleza, convertida de este modo en "mercancía" al servicio del ser humano; teniendo éste la potestad de disponer de ella en su beneficio. Y entonces, en este punto cabe preguntarse, ¿en qué momento histórico podemos situar el inicio de esta lógica con respecto al "uso" de la naturaleza en cuanto que objeto o mercancía a disposición?

"La idea de "sistema económico" que permitió la consolidación de la economía como disciplina [...] tomó cuerpo allá por el siglo XVIII [...] Al proponer la noción de producción -y de su deseable crecimiento - como centro de esta disciplina [...] El crecimiento económico se situaba en correspondencia con el crecimiento físico, no sólode las riquezas renacientes, sino de la propia Tierra que las generaba" (Naredo, 2010: 4-5).

\footnotetext{
${ }^{16}$ Mendez Rocasolano, M.: "Un reto de derecho constitucional y la ecología política: el derecho fundamental al ambiente" en Revista jurídica da UniversidadePortucalense infante D. Enrique n 5 2000. 39- 65.

${ }^{17}$ En este sentido, cabría referirnos a la obra El hombre unidimensional de Marcuse (1968) donde se teoriza sobre las características de la sociedad industrializada, su ideología y las consecuencias antropológicas derivadas de este fenómeno. En esta línea, ampliando esta intepretación hacia su vinculación con respecto al individuo como sujeto trabajador en este contexto, nos parece interesante una referencia al trabajo de Richard Sennet La corrosión del carácter (2001), que indaga en elconcepto de lo que llama "capitalismo flexible" donde el individuo asumirá distintos "fragmentos de trabajo", y en esta representación rutinaria existirá necesariamente un ejercicio de afirmación, negación o reproducción identitarias.
} 
Este fragmento de la obra de José Manuel Naredo (2010) nos sirve para explicar esta mirada antropocéntrica contemporánea que parece dominar, y que comparte esta lógica y puede desembocar en dogmas de uso y disfrute ilimitado de los recursos a disposición. Es precisamente este planteamiento, vinculado también a lo que se refiere como el paradigma tecnocrático, el que se debe cuestionar y rebatir. En esta línea, debemos referirnos de nuevo a la corriente económica que ha venido a llamarse sustantivista a la que se ha hecho referencia.Si la economía no es de aplicación universal, y esta interpretación no es más que un reflejo de la economía moderna occidental, "la escasez no es una condición existencial del hombre sino sólo una condición de la economía capitalista de mercado" (Molina, J.L.; Valenzuela, H., 2007: 60).

Entre los elementos que causan esta degradación ambiental tropezamos con la contaminación. El Papa Francisco señala como una "cultura del descarte" acerca de los objetos que usamos y tiramos convierte todo lo que descartamos en basura. En relación a esto, cabe recordar el informe del Programa de Naciones Unidas para el Medio Ambiente "Waste crime waste risk" ${ }^{\prime 18}$, donde se señala a Europa y Estados Unidos como los países con mayor producción de residuos del mundo, y que además muchos de esos residuos acabarían mediante el comercio ilegal en países africanos (Ghana o Nigeria) o asiáticos (China, Hong Kong, Pakistán o India). Residuos que son potencialmente tóxicos por proceder, por ejemplo, de aparatos electrónicos, una industria que crece a un ritmo vertiginoso, y de las que mayores volúmenes de residuos peligrosos aportan a la cuenta global ${ }^{19}$. Los procesos de exclusión, la expulsión de la sociedad "normalizada" nos recuerda cómo se descartan también los seres humanos considerados "inservibles". De esta forma, cuando los desechos que generamos en el Norte se trasladan al Sur para depositarlos allí, lo que hacemos es simplemente situar en el mismo lugar objetos desechados y seres humanos desechados.

En esta encíclica, Francisco tampoco olvida lo que denomina "pobreza social del agua", en referencia a los problemas de acceso al agua que se tienen sobre todo en África. Tendríamos que sumar a esto la privatización y mercantilización de la gestión del agua en los países que se llaman desarrollados, en los que se discute la dimensión moral y ética de los cortes en el suministro de lo que se considera un elemento fundamental para la realización de todos los DD.HH. De hecho, la ONU en su resolución 64/292 reconoció explícitamente el derecho humano al agua y al saneamiento, exhortando a los países a "intensificar los esfuerzos por proporcionar a toda la población un acceso económico al agua potable y el saneamiento" ${ }^{20}$.

Así, uno tras otro continua nombrando diferentes dificultades por las que atraviesa la tierra como la pérdida de biodiversidad. Es importante subrayar en es te punto que vivimos, según numerosos autores "camino de la sexta gran extinción"” 21 Sin embargo, esta gran extinción sería la primera provocada principalmente por una especie: la humana. Cuando hablamos de pérdida de biodiversidad nos vinculamos con las selvas tropicales, puesto que por ejemplo la Amazonía es una de las reservas de biodiversidad del planeta.Valga como ejemplo sobre conservación de la biodiversidad la iniciativa que propuso el gobierno de Ecuador en 2007, llamada "Yasuni ITT". Esta propuesta aseguraba la no extracción de petróleo de esta región de la Amazonía ecuatoriana (Ishpingo-Tambococha-Tiputini) a cambio de crear un fideicomiso en el que la comunidad internacional pudiera ir aportando al menos la mitad de las ganancias que suponía la extracción y comercialización del crudo. Esta iniciativa defiende que "al dejar el petróleo en tierra, el Ecuador renuncia a un ingreso económico grande, pero, a cambio,

\footnotetext{
${ }^{18}$ UNEP.Waste Crime - Waste Risks: Gaps in Meeting the Global Waste Challenge.2015, pág. 1.

${ }^{19}$ Valga una referencia al concepto de "obsolescencia programada" que explicaría la fabricación de objetos perecederos, con una vida útil de uso limitada de antemano, contraviniendo la existencia de recursos limitados con una "invitación" al consumo periódico "de reposición".

20 ASAMBLEA GENERAL DE LAS NACIONES UNIDAS. Resolución A/RES/64/292, julio de 2010, sobre $E l$ derecho humano al agua y el saneamiento.

${ }^{21}$ OBERHUBER, T. (2004). “Camino de la sexta gran extinción”, El ecologista, $\mathrm{n}^{\circ}$ 41.pág.36.
} Revista de Direito Brasileira | São Paulo, SP | v. 20 | n. 8 | p. 364-377 |Mai./Ago. 2018 
proporciona bienes para toda la humanidad; por lo tanto, tiene que existir corresponsabilidad internacional" ${ }^{\prime 2}$. Sin embargo, transcurridos seis años desde la puesta en marcha de la iniciativa, sólo se aportó por parte de la comunidad internacional el $0,37 \%$ de lo esperado, unos 13,3 millones de dólares según anunció el gobierno ecuatoriano cuando decidió retirar definitivamente la propuesta ${ }^{23}$. El hecho es que la iniciativa fracasó, la comunidad internacional apenas se sintió interpelada por la petición del gobierno ecuatoriano, y tampoco por el impacto que tendría la extracción de petróleo en una de las mayores reservas de biodiversidad del planeta.

Todos estos elementos dibujan una situación de degradación ambiental y también social. Como bien termina exponiendo Francisco, hoy no podemos dejar de reconocer que "un verdadero planteo ecológico se convierte siempre en un planteo social, que debe integrar la justicia en las discusiones sobre el ambiente, para escuchar tanto el clamor de la tierra como el clamor de los pobres" 24 . Ante este paisaje un tanto desolador no deja de ser extraña la falta de reacciones. Es cierto que las reacciones de la política internacional institucional han sido vagas. Sin embargo, no podemos olvidar que históricamente los cambios sociales los han hecho personas, no instituciones.

\subsection{Capítulo 4. Hacia una "ecología integral"}

Ante todas estas pérdidas ambientales, sociales y culturales, el Papa Francisco propone lo que denomina una "ecología integral", explicando que las crisis ambiental y social no existen por separado, sino que responden a una única y compleja crisis socio-ambiental -y, por tanto, o más bien en esencia, una crisis antropológica-. Aboga Francisco I por la constitución/integración de una ecología no sólo ambiental sino también social, cultural y económica. Esto significa que se podría entender la economía como "un sistema de transformación de energía, y de materiales, en productos y servicios útiles y finalmente en residuos" o como se concibe mayoritariamente en la actualidad "como un carrusel o tío-vivo entre consumidores y productores", esto último es lo que Martínez Alier llama la "economía crematística",25. Aquí podemos observar una referencia a aquella "ecología política" a la que se hizo referencia al introducir los preceptos de la Antropología Económica, faltaría entonces esta integración en una solución global que suponga cambios sustanciales en la vida de las personas.

En términos generales, podemos decir que esta "ecología integral" que se propone en el texto establece tres consideraciones: a) una interpelación a ser protectores de la creación; b) la conversión moral en relación al cuidado de aquello que apreciamos; c) llamada al diálogo y a una nueva solidaridad global. La primera de estas consideraciones, ser protectores de la creación, invita a una formación y conciencia como "ciudadanos ecológicos": todos tenemos la obligación, y una cuota de participación, en la protección de lo que el Papa Francisco ha denominado nuestra casa común. En segundo lugar, esta conversión moral urge a una concienciación que supere la coacción de normativas que nos obliguen al cuidado de la naturaleza. Debe iniciarse una concienciación natural, no como un gesto que intente paliar lo que se supone casi destruido, sino con una conciencia profunda y radical. En último lugar, esta ecología integral necesita una nueva solidaridad, que entiende el bien de la persona humana como un valor clave, y que se dirija hacia la búsqueda del bien común universal.

\footnotetext{
${ }^{22}$ FALCONI, F. (2010). "La iniciativa Yasuní ITT es una gran señal para la humanidad”,Revista ecología política, no 39 . pp.83-86.

${ }^{23}$ PRESIDENCIA DE LA REPÚBLICA DEL ECUADOR. Anuncio a la nación: Iniciativa Yasuní ITT, 2013.

${ }^{24}$ Laudato Si, n. 39.

${ }^{25}$ Para avanzar en $\quad$ esta $\quad$ propuesta, véase

http://www.fuhem.es/media/cdv/file/biblioteca/Entrevistas/Entrevista_Joan_Martinez_Alier.pdf
} 
Esta "ecología integral” que propone Francisco I recuerda a lo que Boaventura de Sousa Santos llama "ecología de saberes", es decir, la idea de que solo con el diálogo entre saberes diversos podremos dar respuesta a la crisis que atravesamos. Esta intuición de que la especialización nos hace linces para terrenos muy limitados y ciegos para la mirada amplia, también es asumida por el Santo Padre y propuesta en el desarrollo de su texto al referirse a la importancia de ser conscientes de la interdependencia:

"Porque la persona humana más crece, más madura y más se santifica a medida que entra en relación, cuando sale de sí misma para vivir en comunión con Dios, con los demás y con todas la criaturas" (Laudato Si, 240).

Lo relevante del análisis de la situación actual que hace el Papa Francisco, nos parece que está en la no diferenciación, es decir, en afirmar que "no hay dos crisis separadas, una ambiental y otra social, sino uno sola y compleja crisis socio-ambiental" 26 . Y en este sentido, apelamos a la "mirada antropológica" a la que se refiere la profesora María Isabel Jociles (1999) como esa capacidad que permite esta disciplina desde su enfoque particular, atendiendo a lo concreto, entendiéndole en relación a su contexto particular. En este sentido, cabe apelar a la llamada del Santo Padre en relación a la visión cultural que se debe tener en esta urgencia; desde nuestros hermanos indígenas y campesinos en Latinoamérica, hasta los perfiles de ciudadanía más diversos que podemos encontrarnos en Europa. Y en esta perspectiva global, pero que no debe obviar las particularidades de cada territorio, no podemos olvidar que son los pobres quienes sufren esta crisis, y los efectos de la degradación ecológica en concreto, con más intensidad:

“[...] no podemos dejar de reconocer que un verdadero planteo ecológico se convierte siempre en un planteo social, que debe integrar la justicia en las discusiones sobre el ambiente, para escuchar tanto el clamor de la tierra como el clamor de los pobres"27.

\section{CONCLUSIONES}

En primer lugar, debemos recordar que, si bien los temas sobre el cuidado de la creación, el desarrollo humano integral, la preocupación por los pobres y las futuras generaciones ya tenían una clara presencia en las homilías, discursos y mensajes del Papa Francisco, es en esta Carta Encíclica donde podemos decir que encuentran su momento más amplio, centrado en lo que podemos llamar ecología natural y humana.

Como conclusiones de esta reflexión que aquí presentemos, podemos referirnos a la necesidad de un diálogo a nivel internacional sobre la relación hombre-naturaleza, de manera que proponga pactos vinculantes que avancen en la línea que en el texto de Francisco podemos leer. Cabe una referencia también a la necesidad de construcción de nuevas políticas tanto nacionales como locales, que supongan transparencia en la gestión y toma de decisiones que tengan consecuencias directas sobre el territorio, los hábitats y los ecosistemas. Esto último adquiere sentido cuando caemos en la cuenta de que la solución pasa también por un dialogo y alianza entre política y economía, en el que se traten los límites al mercado y de la mayor responsabilidad de los más poderosos acerca de la consecución del Bien Común.

El crecimiento económico de los llamados países emergentes se basa en el modelo de desarrollo capitalista, un sistema productivo responsable de nuestra huella ecológica. Las consecuencias de este modelo provoca que el planeta ya no sea capaz de regenerar buena parte de

${ }^{26}$ Laudato Si, n. 139.

Revista de Direito Brasileira | São Paulo, SP | v. 20 | n. 8 | p. 364-377 |Mai./Ago. 2018 
lo que consumimos, y los expertos advierten de que si se mantiene el ritmo actual de consumo, en el año 2050 necesitaríamos el equivalente a tres planetas para abastecernos. He aquí la llamada a una "revolución antropológica" que cuestione la lógica de un sistema depredador y no sostenible, y para ello hemos apelado a lo que hemos dado a llamar una pedagogía que conciencia y construya una nueva ciudadanía crítica.

En suma, en este artículo nos ha interesado señalar que en esta crisis ecológica, económica, social y cultural que venimos atravesando, se han ido priorizando unos determinados valores, de manera que se ha ido generando una lógica común, compartida por muchos habitantes del planeta y que debería ponerse en cuestión. De ahí la necesidad de apuntar hacia una "ética ecológica" que actúe como regeneradora y que encamine hacia una nueva forma de estar en el mundo.

\section{BIBLIOGRAFÍA}

BERGOGLIO, J.: Laudato si. Verbo divino, 2015.

CARRERA I CARRERA, J; PUIG, Ll.: Hacia una ecología integral, Cuadernos Cristianisme i Justícia. Ediciones Rondas, 2017.

CAYUELA SÁNCHEZ, S.: "Una nueva antropología económica para el estudio de las sociedades complejas: aplicación del análisis de los modos de vida a la pequeña agricultura" en: SCHRIEWER, Klaus, Salvador CAYUELA SÁNCHEZ (eds.): Perspectivas antropológicas: herramientas para el análisis de las sociedades europeas . Murcia, Münster y New York, Editum y Waxmann, págs. 323-368, 2014.

COMAS D’ARGEMIR, D: Antropología económica, Ariel, Barcelona, 1998.

FALCONI, I.: “La iniciativa Yasuní ITT es una gran señal para la humanidad” en Revista ecología política, $\mathrm{n}^{\circ}$ 39, 2010.

FRIEDMANN, H.: "Household Production and the National Economy: Concepts for the Analysis of Agrarian Formations" en The Journal of Peasant Studies, No 2, Vol. 7, 1980, pp. 158-184, 1980.

HOBSBAWM, E.: La era del capital 1848-1875. Crítica, 2009.

GARCÍA ALLUT, A.: "La pesca artesanal, el cambio y la patrimonialización del conocimiento" en Revista ph, n 44, Especial, 2004.

GUDYNAS, E.:Ecología, economía y ética del desarrollo sostenible. Ediciones Abya-Yala, 2004.

HERSKOVITS, M.: Antropología económica .Fondo de Cultura económica, 1952.

LÓPEZ MARTÍNEZ, G.: "Culturas laborales: distintas formas de ser pescador en la costa murciana” en Revista de antropología experimental, No. 16, p. 251-262, 2016. 
MARCUSE, H.: El hombre unidimensional. Ensayo sobre la ideología de la sociedad industrial avanzada. Seix Barral, 1968.

MARTÍNEZ NAVARRO, E.: ¿Crisis de civilización? Cambio de paradigma. VI Seminario Los Nuevos Escenarios del Desarrollo Humano, Fundación Pablo VI, Facultad de Ciencias Políticas y Sociología León XIII, 2007.

MAUCOURANT, J.: Descubrir a Polanyi. Siglo XXI, 2006.

MÉNDEZ ROCASOLANO, M.: El Derecho, el hombre y la Tierra. Fundamentos y defensa jurídica del Derecho al medio ambiente, Dykinson 2017.

MENDEZ ROCASOLANO, M.: "Un reto de derecho constitucional y la ecología política: el derecho fundamental al ambiente" en Revista jurídica da UniversidadePortucalense Infante D. Enrique n 5. Oporto, 2000.

MESEGUER SÁNCHEZ, V. RSC: "Una interpelación al derecho internacional público"en: NICOLÁS GUARDIOLA, Juan.; GINER ALEGRÍA, César.Augusto. Empresas, Derechos Humanos y RSC: una mirada holística desde las Ciencias Sociales y Jurídicas. Thomson Reuters Aranzadi, 2016.

MOLINA, J.L.; VALENZUELA, H.: Invitación a la antropología económica. Ediciones Bellaterra, 2007.

NAREDO, J. M.: Raíces económicas del deterioro ecológico y social: más allá de los dogmas. Editorial Siglo XXI, 2010.

OBERHUBER, T.: “Camino de la sexta gran extinción” en El ecologista, n 41, 2004.

POLANYI, K.: La gran transformación. Crítica del liberalismo económico. La Piqueta, 1989.

SCHRIEWER, K.: Ecologismo y naturaleza. Percepción y concepto de naturaleza en el movimiento de protección ambiental en Alemania. Ediciones Isabor, 2012.

SENNET, R.: La corrosión del carácter. Las consecuencias personales del trabajo en el nuevo capitalismo, Anagrama, 2001.

STEWARD, J.: Theory of Culture Change: The Methodology of Multilinear Evolution, 1995.

TAIBO, C.: El decrecimiento explicado con sencillez. Editorial La Catarata, 2011.

WHITE, L.: The Science of Culture: A study of man and civilization. Straus and Giroux, 1949. 